\title{
Reconstruction of the left-sided brachiocephalic trunk after vascular ring operation in left-handed child with Kommerell's diverticulum
}

\author{
Ireneusz Haponiuk', Konrad Paczkowski', Maciej Chojnicki', Radosław Jaworski ${ }^{1}$, Mariusz Steffens ${ }^{1}$, \\ Aneta Szofer-Sendrowska' ${ }^{1}$, Ewelina Kwaśniak', Jacek Zieliński², Katarzyna Gierat-Haponiuk ${ }^{3}$ \\ 1Department of Paediatric Cardiac Surgery, Mikołaj Kopernik Pomeranian Centre of Traumatology, Gdansk, Poland \\ 2Department of Surgical Oncology, Medical University of Gdansk, Poland \\ ${ }^{3}$ Department of Rehabilitation, Medical University of Gdansk, Poland
}

Postep Kardiol Inter 2013; 9, 2 (32): 146-149

DOI: $10.5114 /$ pwki.2013.35449

\begin{abstract}
We report a case of a 2-year-old girl with prenatal diagnosis of vascular ring composed of a right-sided aortic arch, a left ligamentum arteriosum, and a left subclavian artery (arteria lusoria sin) originating from a retroesophageal Kommerell's diverticulum, who was referred for surgery with symptoms related to local compression - severe dysphagia and respiratory disorders. Through the left posterolateral thoracotomy, a ligamentum arteriosum between the Kommerell's diverticulum and the left pulmonary artery was divided and because of left-handedness of the child a brachiocephalic trunk was reconstructed in the fashion of anastomosis of the left subclavian artery and the left common carotid artery, originating from the ascending aorta.
\end{abstract}

Key words: congenital heart defects, vascular ring, Kommerell's diverticulum, pediatric cardiac surgery.

\section{Introduction}

Vascular rings are a rare disease of large vascular trunks and their branches account for $0.7-1.3 \%$ of congenital heart diseases [1]. A right aortic arch with a left arterial ligament is the second most common vascular ring causing compression on the trachea and the esophagus in children. This form of vascular ring is less likely related to symptoms and they occur at an older age in comparison to the most frequent form of the ring - a double aortic arch [2]. In some patients with right aortic arch and left arterial ligament the left subclavian artery originates from the Kommerell's diverticulum and passes behind the esophagus and is known as a lusorian artery. This relation of vessels accounts for $6 \%$ of aortic arch anomalies, which reflects $0.042 \%$ of all cardiovascular malformations in children [1]. Kommerell's diverticulum may be an additional, and independent from the left subclavian artery, structure compressing the trachea and the esophagus $[3,4]$. Prenatal diagnosis of positional anomalies of the aortic arch may suggest the presence of a vascular ring, which requires further detailed study after childbirth [5].

\section{Case report}

A 2-year old girl was admitted to the Department of Pediatric Cardiac Surgery of the Pomeranian Traumatology Center in Gdansk with prenatally diagnosed congenital heart disease in the form of a vascular ring with the right aortic arch and symptoms of compression of organs encircled by the ring - breathing disorder, suspicion of tracheomalacia, recurrent upper and lower respiratory tract infections and severe dysphagia. The child remained under the care of a pediatric reference center, where conservative therapy was continued with the use of bronchodilators and the need of feeding with small amounts of mixed semi-liquid fluids. Imaging studies (echocardiography, angio-CT) performed at the age of 2 years confirmed the presence of the vascular ring as suggested earlier, consisting of the right aortic arch and left subclavian artery with retroesophageal course originating from the Kommerell's diverticulum to the left of the right aortic arch and arterial ligament between the Kommerell's diverticulum and the left pulmonary artery (Figures 1 and 2). The girl was qualified for immediate surgery to release the vascular ring. Because of the declared left-

\section{Corresponding author:}

Konrad Paczkowski, Department of Paediatric Cardiac Surgery, Mikołaj Kopernik Pomeranian Centre of Traumatology, 1-6 Nowe Ogrody St, 80-803 Gdansk, Poland, tel.: +48 509392 484, e-mail: konradpaczkowski@gmail.com

Received: 7.12.2012, accepted: 9.05.2013. 


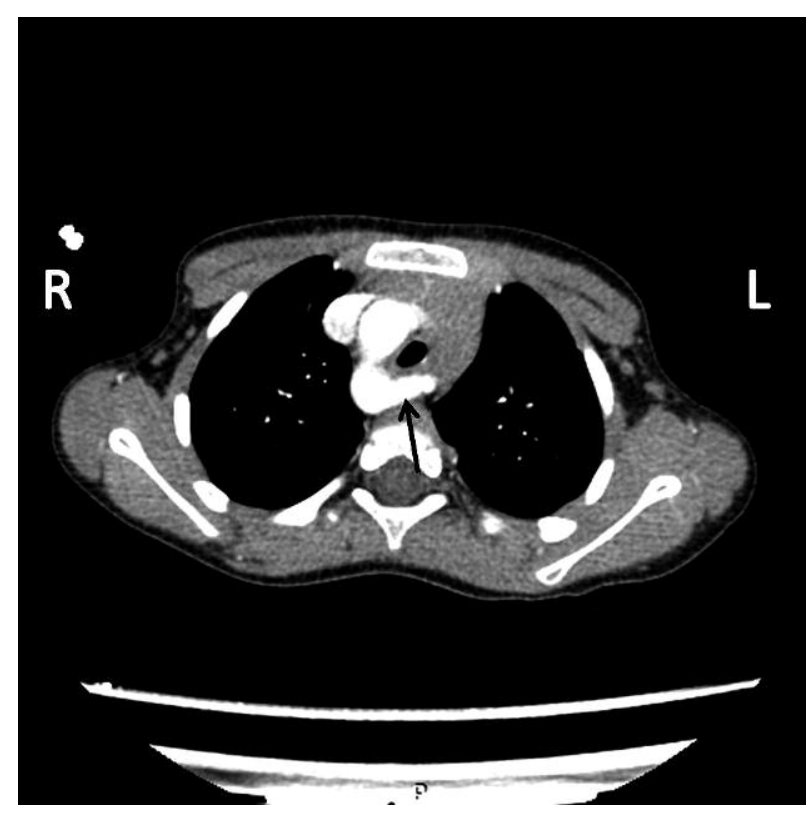

Fig. 1. Computed tomography of the child's chest showing right aortic arch with visible retroesophageal left subclavian artery (lusorian artery) and the Kommerell's diverticulum (arrow). The esophagus is compressed by the Kommerell's diverticulum (completely closed in this projection) and the trachea has signs of cartilage malacia

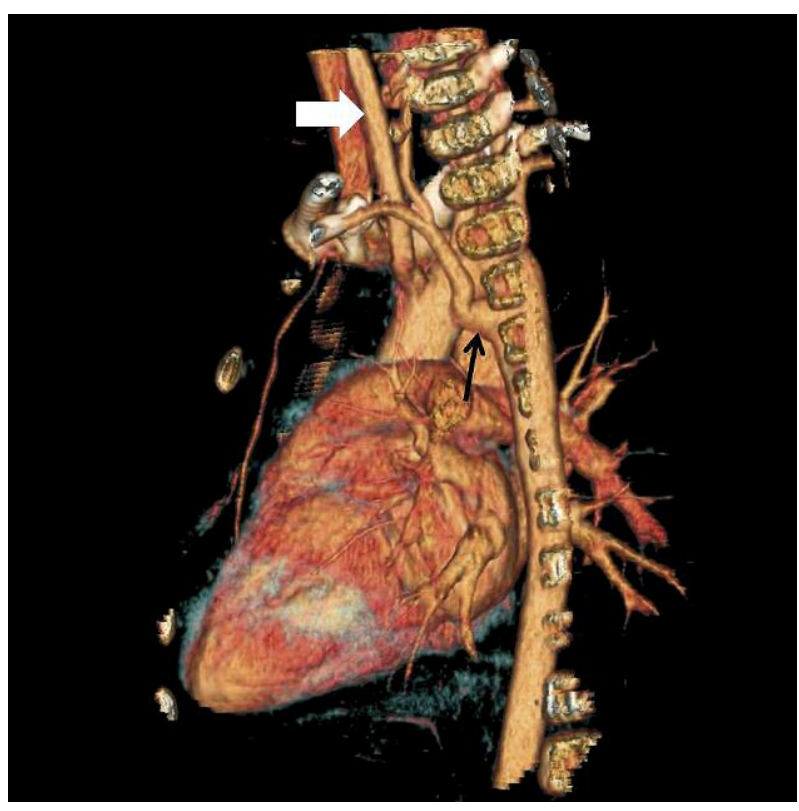

Fig. 2. Three-dimensional reconstruction of the heart and right aortic arch with side branches - the Kommerell's diverticulum (black arrow), left subclavian artery originating from the Kommerell's diverticulum (a vessel running up), left common carotid artery originating from the ascending aorta (white arrow)

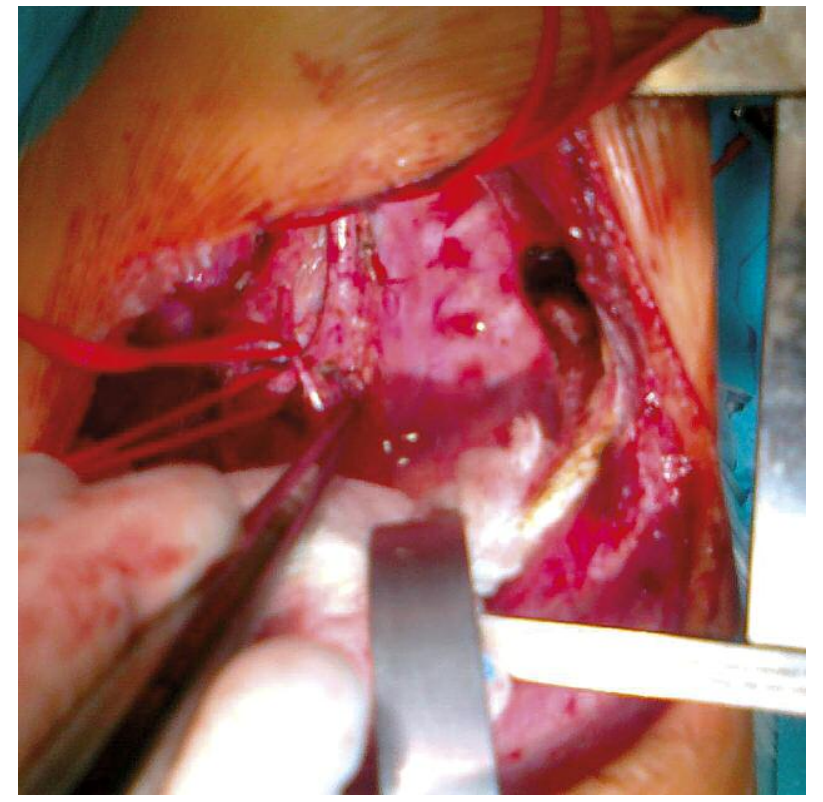

Fig. 3. Intra-operatively detected pulling up of the Kommerell's diverticulum by filled left subclavian artery, which was additionally increasing the compression on the esophagus (almost closed) and the trachea

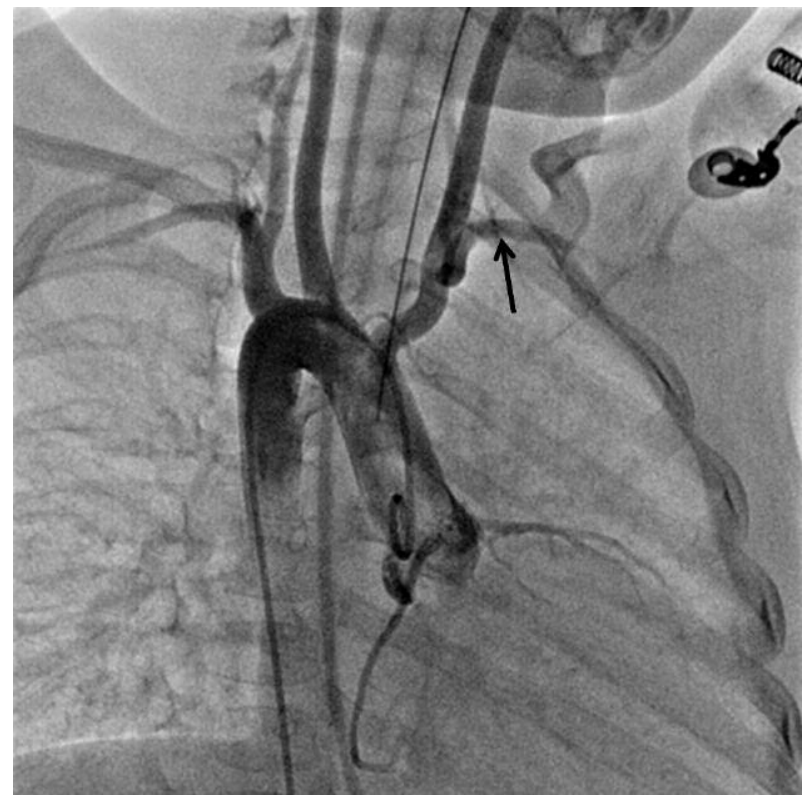

Fig. 4. Diagnostic heart catheterization performed 3 weeks after release of the vascular ring and reconstruction of the brachiocephalic trunk in a child with right aortic arch. Arrows show a normal inflow to the left subclavian artery from the reconstructed brachiocephalic trunk 
handedness and the patient's age, a decision was made to reconstruct the arterial supply to the left upper extremity from the aorta with transposition of arteries to the anatomically correct left side to fully cure the patient and to avoid growth retardation and ensure normal quality of life of the child. The area of vessels forming the vascular ring consisting of the Kommerell's diverticulum compressing the esophagus and the trachea and the arterial ligament connecting the left pulmonary artery to the diverticulum was approached through the left postero-lateral thoracotomy. Pulling up of the Kommerell's diverticulum by the filled left subclavian artery was confirmed; it was further increasing the pressure on the esophagus (almost completely closed) and the trachea. The arterial ligament stretching between the Kommerell's diverticulum and the left pulmonary artery was dissected, ligated and then separated and sutured on both sides, which released the pressure on the esophagus. Signs of cartilage malacia of the trachea at the side of the ligament were macroscopically confirmed after the ligament separation. The left common carotid artery was identified and a decision to reconstruct the brachiocephalic trunk in this variant was made (as the first brain-supplying vessel originating from the ascending aorta). The lusorian artery was cut off the Kommerell's diverticulum and the diverticulum was additionally released by its diffused dissection from the esophagus and the peri-vertebral area to obtain displacement of the diverticulum to the right. Subsequently, the left subclavian artery was anastomosed with the left common carotid artery originating from the right aortic arch by an end-to-side method. Lymphorrhea occurred in the postoperative course; it was probably related to the broad dissection of the posterior mediastinum during the procedure. A left pleural drainage was installed and treatment with somatostatin was started with complete parenteral nutrition followed by low-fat restricted diet, which led to cessation of symptoms after 5 days [6]. The girl was discharged home in improved clinical condition with diminishing symptoms of dysphagia. A control diagnostic heart catheterization after 3 weeks confirmed the normal inflow to the left subclavian artery from the reconstructed brachiocephalic trunk without signs of compression on the trachea or the esophagus (Figure 4). Respiratory symptoms and dysphagia resolved completely, bronchodilators were discontinued and the child returned to a normal diet without any restrictions or signs of dysphagia.

\section{Discussion}

Kommerell's diverticulum is an embryologic remnant of the fourth arterial arch - left in the case of the right aortic arch, or right in the case of the left aortic arch [7]. This vessel was described for the first time in 1936 by Kommerell [8], a pioneer of the in vivo diagnosis of vascular rings by means of barium esophagography. In patients with a right aortic arch the Kommerell's diverticulum is often the origin of the left subclavian artery and arterial duct (or after its closure - the arterial ligament), which together form a vascular ring. Patients with vascular rings may present various clinical symptoms ranging from severe forms of dysphagia and respiratory disorders with malacia of the tracheal cartilages present already in neonates to completely asymptomatic adults. Vascular rings may be diagnosed early by prenatal echocardiography, but it is impossible to determine the severity of the disease at this stage. Therefore it is important to combine the prenatal diagnostics and postnatal imaging diagnostics to qualify the child for surgery, before the onset of secondary and severe complications such as tracheomalacia and dilation of the esophagus $[5,9]$. The value of barium esophagography is currently smaller and preferred studies include magnetic resonance imaging and computed tomography $[4,10]$. These studies permit a threedimensional image reconstruction of vascular anomalies and comparison of severity of compression of the organs encircled by the ring with clinical symptoms. An echocardiographic examination of the vascular rings has only supplementary value in planning of the cardio-surgical interventions, indicates the presence of anomalies of the aortic arch and is useful in assessment of concomitant heart diseases. The first description of surgical treatment of vascular rings was presented by Gross [11]. A classic approach to surgical treatment of vascular rings in the form of the right aortic arch with the left arterial ligament consists of separation of the arterial ligament with release of fibers compressing the esophagus and the trachea [12]. In case of significant compression on the esophagus caused by the retroesophageal subclavian artery it was recommended to cut it proximally to the aorta and secure both ends. After surgery blood flow to the upper left extremity depended completely on collateral circulation, which often led to its hypoplasia and stealing syndrome from the cerebral circulation. Therefore currently some authors recommend cutting the lusorian artery off and connecting it to the common carotid artery as the primary surgical approach [3, 4, 10, 13]. According to our knowledge, in the world literature there have been reported 32 such operations in children during the last 15 years $[3,4,13,14]$. In the present case, with the described anatomical variant, isolated dissection of the arterial ligament might not have been, in our opinion, sufficient. According to data from the literature, this management leads to recurrences of compression symptoms [3, 13], which is evidently caused by the retroesophageal lusorian artery and dilation of the remnant Kommerell's diverticulum. Cutting off the subclavian artery without its reimplantation might have increased the risk of the stealing syndrome to the subclavian artery. The patient's age was another non-negligible factor for the development of collateral circulation in the extremity without an inflow from the subclavian artery, which in consequence might have led to impaired function of this extremity. In the present case the child was left-handed, so preservation of the normal function of the dominant upper extremity was, in our opinion, extremely important 
for the general child's performance in the future. Control imaging studies, functional improvement and subjective feeling of undisturbed swallowing and breathing confirm the good effect of treatment and effectiveness of the chosen strategy despite relatively late qualification for the procedure. Despite the good final effect of the treatment confirmed by imaging studies and clinical improvement, a patient with a symptomatic vascular ring should be referred for surgical treatment at the time of diagnosis. Prenatal diagnosis of the positional anomalies of the aortic arch should suggest the presence of a vascular ring, but without a doubt requires an additional diagnostic work-up after childbirth, because early surgical treatment prevents the onset of life-threatening symptoms of compression.

\section{References}

1. Weinberg PM. Aortic arch anomalies. In: Moss and Adams heart disease in infants, children and adolescents. Williams \& Wilkins, Baltimore 1992.

2. Skalski J, Haponiuk I, Szkutnik M, Pypłacz D. Cervical aortic arch. The report of successful, two-stage surgical treatment. Minerva Chirurgia 2007; 20: 313-317.

3. Backer CL, Hillman N, Mavroudis C, Holinger LD. Resection of Kommerell's diverticulum and left subclavian artery transfer for recurrent symptoms after vascular ring division. Eur J Cardiothorac Surg 2002; 22: 64-69.

4. Backer CL, Russell HM, Wurlitzer KC, et al. Primary resection of Kommerell diverticulum and left subclavian artery transfer. Ann Thorac Surg 2012; 94: 1612-1617.

5. Olivieri LJ, Cross RR, Donofrio MT. Influence of fetal diagnosis on the clinical presentation of a vascular ring. Pediatr Cardiol 2012; 33: 351-353.

6. Rokicki W, Rokicki M, Filipowski M, et al. Chylothorax as a problem in thoracic and cardiac surgery. Part II. Treatment. The proceedings algorithm. Kardiochir Torakochir Pol 2011; 8: 361-365.

7. Skalski JH, Haponiuk I, Kovalenko I. Szyjny tuk aorty. In: Kardiochirurgia dziecięca (Polish). Skalski J, Religi Z (eds.). Publishing Śląsk, Katowice 2004; 27: 374-380.

8. Kommerell B. Verlagerung des ösophagus durch eine abnorm verlaufende arteria subclavia dextra (arteria lusoria). Fortschr Geb Roentgenstrahlen 1936; 54: 590-595.

9. Li S, Luo G, Norwitz ER, et al. Prenatal diagnosis of congenital vascular rings and slings: sonographic features and perinatal outcome in 81 consecutive cases. Prenat Diagn 2011; 31: 334-346.

10. Backer CL, Mavroudis C, Rigsby CK, Holinger LD. Trends in vascular ring surgery. J Thorac Cardiovasc Surg 2005; 129: 1339-1347.

11. Gross RE. Surgical relief for tracheal obstruction from a vascular ring. N Engl J Med 1945; 233: 586-590.

12. Ruzmetov M, Vijay P, Rodefeld MD, et al. Follow-up of surgical correction of aortic arch anomalies causing tracheoesophageal compression: a 38-year single institution experience. J Pediatr Surg 2009; 44: 1328-1332.

13. Shinkawa T, Greenberg SB, Jaquiss RD, Imamura M. Primary translocation of aberrant left subclavian artery for children with symptomatic vascular ring. Ann Thorac Surg 2012; 93: 1262-1265.

14. Abuchaim DC, Burger M, Berwanger SA, Faraco DL. Vascular ring related to Kommerell diverticula: case report. Rev Bras Cir Cardiovasc 2007; 22: 352-354. 